\title{
Metodologia de resolução de problemas: concepções e estratégias de ensino
}

\section{RESUMO}

Juliana Meneghelli uliana.meneghelli@hotmail.com 0000-0001-5308-8999 Universidade Regional de Blumenau, Blumenau, Santa Catarina

\section{Dionei Cardozo} dionei.cardozo95@gmail.com 0000-0003-0850-9664 Universidade Regional de Blumenau, Blumenau, Santa Catarina

Janaína Poffo Possamai anainap@furb.br 0000-0003-3131-9316 Universidade Regional de Blumenau, Blumenau, Santa Catarina

Viviane Clotilde da Silva vcs@furb.br

0000-0002-0315-6532

Universidade Regional de Blumenau, Blumenau, Santa Catarina

\begin{abstract}
Essa pesquisa bibliográfica tem como objetivo apresentar algumas reflexões acerca da utilização da metodologia de resolução de problemas no contexto escolar. Inicialmente, resgata-se algumas concepções históricas sobre a resolução de problemas, relacionando-a com o Movimento da Matemática Moderna. Posteriormente, diferencia-se exercício, questão contextualizada e problema, uma vez que por vezes são utilizados erroneamente como sinônimos. Em seguida, analisa-se as contribuições e limitações do uso do ensino sobre, para e através da resolução de problemas no processo de ensino e aprendizagem de conceitos matemáticos e, para finalizar, apresenta-se uma proposta de ensino através da resolução de problemas. Essa proposta de atividade é destinada para estudantes da 2a série do Ensino Médio e tem como objetivo auxiliar na construção de conceitos da Geometria Espacial. Espera-se com essa reflexão, despertar nos professores o interesse em utilizar a resolução de problemas em sala de aula, com o intuito de promover uma aprendizagem significativa.
\end{abstract}

PALAVRAS-CHAVE: Ensino de Matemática. Resolução de problemas. Sala de aula. 


\section{INTRODUÇÃO}

Analisada perante um contexto histórico, a Matemática tem suas origens relacionadas com os processos de contagem, em especial, ao controle de bens, que gradativamente permitiu às primeiras civilizações criarem sistemas de numeração que possibilitassem um efetivo domínio de terras, plantações ou criação de animais. Tais sistemas, contribuíram para o advento do comércio e, também, para posteriormente, um desenvolvimento mais amplo e sofisticado da Matemática.

Pode-se considerar que, nas primeiras civilizações, os processos matemáticos foram construídos a partir das necessidades básicas das pessoas. Em outras palavras, a Matemática surgiu como uma ferramenta que permitia dar resposta a alguns dos problemas que permeavam a sociedade de cada período histórico. Hoje, em muitas situações, isto ainda acontece. O que mostra a inegável a importância que os problemas possuem no desenvolvimento da Matemática.

Entretanto, mesmo reconhecendo o papel que os problemas tiveram durante o desenvolvimento da Matemática, somente no final do século XX é que passou a ser estudada uma forma de utilizá-los como metodologia de ensino dentro da Matemática. Esta prática, teve grande influência do livro "How to Solve $1 t^{\prime 1}$ de George Polya, publicado em 1945. Este trabalho trouxe a preocupação, no ensino da Matemática, de como os problemas são resolvidos, elaborando técnicas que pudessem ser utilizadas em qualquer situação que se faz necessária a busca de uma solução. Tais técnicas, descritas por Polya, são fundamentadas a partir de princípios heurísticos que buscam definir os métodos utilizados na descoberta de soluções. Nesses últimos anos, diversas novas pesquisas foram conduzidas nesta área e possibilitaram à resolução de problemas uma posição de destaque dentro do Ensino da Matemática.

Contudo, quando se fala em "solucionar problemas", especialmente no âmbito escolar, existe uma ligação natural com a ideia de resolver questões de Matemática. Nesse contexto, o termo "problema" torna-se pretexto como enfoque de qualquer atividade matemática, causando assim, uma visão banalizada da palavra. Vila e Callejo (2006, p. 27, grifo do autor) corroboram essa ideia ao afirmar que,

[...] o termo problema está muito desgastado no contexto escolar, pois vem sendo utilizado para se referir a uma ampla tipologia de atividades propostas aos alunos com finalidades muito díspares e, principalmente, com um aspecto comum: exige-se aplicar diferentes conhecimentos, habilidades e capacidades que normalmente fazem parte da programação de matemática.

Situado a esse contexto, propõe-se com este trabalho uma reflexão acerca de como utilizar a metodologia de resolução de problemas no contexto escolar. Pretende-se fomentar uma discussão das diversas ferramentas matemáticas que, muitas vezes, são utilizadas como sinônimos de problemas, mas que não constituem na prática a utilização da metodologia de ensino e aprendizagem definida como resolução de problemas. Após essa discussão teórica, apresenta-se, para fins de exemplificação de como essa metodologia pode ser utilizada, uma situação descrita em um livro didático que pode ser readequada para um

${ }^{1}$ Título no Brasil: "A arte de resolver problemas".

Página | 212 
problema, proposto à estudantes da 2a série do Ensino Médio. Ao fim, espera-se com este estudo, esclarecer os componentes necessários para a devida efetivação desta prática no principal ambiente que se propõe a construção do pensamento, a sala de aula.

\section{CONTEXTO HISTÓRICO DA CONSOLIDAÇÃO DA METODOLOGIA DE RESOLUÇÃO DE PROBLEMAS}

O ensino da Matemática no início do século XX estava baseado na tendência formalista clássica e priorizava a memorização e repetição mecânica de algoritmos e técnicas e os estudantes eram avaliados, preponderantemente, por meio de testes, sendo a conclusão de que sabiam algo obtida pela observação do potencial de reprodução do que o professor havia mostrado (FIORENTINI, 1995). Anos depois, uma nova orientação direcionava o processo no sentido de que os estudantes aprendessem Matemática por compreensão, ou seja, o estudante deveria entender o que o professor falava, porém, o mesmo não participava da construção dos conceitos, era um mero expectador (ONUCHIC, 1999). Essas formas de ensino não representaram o sucesso esperado quanto à aprendizagem, sendo poucos os estudantes que tiveram êxito em compreender a Matemática (ONUCHIC, ALLEVATO, 2004).

Paralelamente a essa reforma do modo de se ensinar Matemática, a resolução de problemas começava a conquistar seu espaço. Em especial, a partir da publicação dos trabalhos de Polya. O método heurístico de Polya para a resolução de um problema não se destinava apenas aos problemas matemáticos, mas, também, a qualquer situação onde a resposta e o caminho a ser seguido pela busca da solução não estivessem claramente definidos no enunciado da questão (ALLEVATO, 2014).

As insatisfações perante o ensino da Matemática em um contexto mundial, fizeram com que iniciasse, dentre as décadas de 50 e 70, um movimento que tinha como objetivo realizar grandes reformas na Matemática que era ensinada em sala de aula, bem como, proporcionar um momento para discussões e trocas de ideias acerca do seu ensino, este movimento ficou conhecido como Movimento da Matemática Moderna (MMM).

Em meio a este contexto, para Dobrowolski e Pinto (2009, p. 4165) o Movimento da Matemática Moderna "almejava tornar o conteúdo matemático escolar mais vinculado com o avanço tecnológico e assim contribuir para os progressos científicos da sociedade que estava em pleno desenvolvimento".

Nas palavras de Onuchic (1999, p. 202), o Movimento da Matemática Moderna:

\footnotetext{
Apresentava uma matemática estruturada, apoiada em estruturas lógica, algébrica, topológica e de ordem e enfatizava a teoria dos conjuntos. Realçava muitas propriedades, tinha preocupações excessivas com abstrações matemáticas e representava uma linguagem matemática universal, concisa e precisa. Entretanto, acentuava o ensino de símbolos e uma terminologia complexa que comprometia o aprendizado.
} 
A proposta não conseguiu atingir os objetivos almejados de modo que os índices de aprendizagem da Matemática continuavam baixos. Berti $(2005$, p. 12) corrobora com esta ideia salientando que "os problemas foram agravados pela falta de preparo dos professores que foram obrigados a ensinar uma Matemática para cujos métodos não foram preparados. Portanto, a Matemática Moderna, também, não conseguiu resolver o problema do ensino". Como agravante, Onuchic (1999, p. 203) cita que as dificuldades encontradas pelos estudantes diante do movimento se encontravam no fato de eles não conseguirem perceber "a ligação que todas aquelas propriedades enunciadas tinham a ver com a matemática dos problemas e, principalmente, com a matemática usada fora da escola".

Diante destas circunstâncias, na busca de uma metodologia que auxiliasse na aprendizagem da Matemática por parte dos alunos, a resolução de problemas recebe maior atenção perante pesquisadores do ensino da Matemática, conforme enfatiza Onuchic (1999, p. 204): "No final dos anos 70, a resolução de problemas ganhou espaço no mundo inteiro. Começou o movimento a favor do ensino de resolução de problemas". Estudos passam a ser amplamente difundidos, discutidos e aplicados em uma escala maior em todo mundo, a partir da publicação do documento "Uma Agenda para Ação - Recomendações para a Matemática Escolar para a década de $1980^{\prime 2}$ publicado pelo Conselho Nacional de Professores de Matemática ${ }^{3}$ (NCTM), nos Estados Unidos da América. Neste documento, recomenda-se que: "A resolução de problemas seja o foco da matemática escolar nos anos 80" (NCTM, 1980, p. 1, tradução nossa).

Em especial, destaca-se que "no Brasil, na década de 80 , a resolução de problemas passa a ser difundida entre os educadores pela entrada no país das publicações norte-americanas e por meio dos primeiros mestrados e doutorados de brasileiros orientados por pesquisadores daquele país" (DINIZ, 2011, p. 2). Com isso os currículos brasileiros passaram a considerar a resolução de problemas como uma medida importante e bem aceita, uma vez que os materiais instrucionais, tanto para professores como para estudantes, passaram a ser úteis para o ensino e aprendizagem da Matemática (ONUCHIC, 1999).

A partir dessas concepções e com vistas aos aspectos históricos, a resolução de problemas ganhou destaque no âmbito mundial, especialmente por meio das pesquisas e materiais voltados ao ensino da Matemática, sendo atualmente considerada como uma metodologia utilizada não apenas para fixação de conteúdo, mas, principalmente, como uma importante ferramenta que auxilia na construção do conhecimento matemático e que permite ao estudante desempenhar um papel ativo e significativo em sua aprendizagem.

\section{PROBLEMAS X EXERCÍCIOS, QUANDO UTILIZAR?}

Após esta abordagem histórica sobre como a resolução de problemas se tornou uma metodologia para o ensino da matemática, considera-se relevante salientar que ao referir-se a esta metodologia, é necessário deixar explícito qual o real sentido da palavra problema nesse contexto.

\footnotetext{
2 "An Agenda for Action - recommendations for School Mathematics of the 1980s".

3 "National Council of Teachers of Mathematics".

Página | 214
} 
É comum haver confusões acerca de quando a atividade desenvolvida se trata de resolução de problemas ou de exercícios dentro do ensino da Matemática, visto que "[...] a distinção entre problema e exercício é bastante sutil, não devendo ser especificada em termos absolutos" (PEDUZZI, 1997, p. 230). Contudo, quer-se a seguir, distingui-los e mostrar de maneira mais concisa em quais situações se faz necessária a utilização de um problema ou de um exercício e expor que ambos são úteis no ensino da Matemática, mas devem ser utilizados em situações diferenciadas.

Para Onuchic e Allevato (2011, p. 81) um problema "é tudo aquilo que não se sabe fazer, mas que se está interessado em fazer". Essa definição ampla refere-se a qualquer problema, porém, no contexto de ensino da Matemática pode-se apontar mais precisamente um problema matemático como sendo uma determinada situação que não seja de total conhecimento do estudante e que não estejam claramente explícitos quais métodos ou caminhos devem ser utilizados em sua resolução, conforme define Vila e Callejo (2006, p. 27):

\footnotetext{
Reservaremos, pois, o termo problema para designar uma situação, proposta com finalidade educativa, que propõe uma questão matemática cujo método de solução não é imediatamente acessível ao aluno/resolvedor ou ao grupo de alunos que tenta resolvê-la, porque não dispõe de um algoritmo que relaciona os dados e a incógnita ou de um processo que identifique automaticamente os dados com a conclusão e, portanto, deverá buscar, investigar, estabelecer relações e envolver suas emoções para enfrentar uma situação nova.
}

Os mesmos autores defendem ainda, o aspecto contextualizado que um problema deve abranger com o intuito de fazer os estudantes sentirem-se instigados a iniciar sua resolução e apontam que "[...] ininterruptamente e desde cedo na vida dos alunos, os problemas devem originar-se, desenvolver-se e ser revisados em contextos da vida cotidiana" (VILA; CALLEJO, 2006, p. 133). Com isso faz-se necessário ao professor saber escolher a situação a ser representada a partir de um problema de modo que ela permita desenvolver ou praticar determinado conteúdo matemático em sua resolução e despertar o interesse dos estudantes envolvidos. Para tanto, é necessário conhecer o grupo de estudantes de forma que a situação proposta realmente se torne um problema para eles.

Nesse sentido, problemas abertos constituem uma importante ferramenta matemática que pode fazer a conexão das situações vivenciadas pelos estudantes com os conteúdos a serem ensinados, conforme enfatizam Pozo e Angón (1998, p. 160): "Para que se configurem verdadeiros problemas que obriguem o aluno a tomar decisões, planejar e recorrer à sua bagagem de conceitos e procedimentos adquiridos, é preciso que as tarefas sejam abertas, diferentes umas das outras, ou seja, imprevisíveis". Clement e Terrazan (2011, p. 91) corroboram com a implementação de uma prática voltada a utilização de problemas abertos quando afirmam que:

É sempre importante que propicie um trabalho em grupo e que envolva situações vivenciais, as quais devem ser apresentadas o mais abertas possíveis, de modo que estimulem os alunos a levantarem as 'variáveis' envolvidas, os parâmetros relevantes e as possibilidades de resolução, exigindo, assim, uma mobilização dos conhecimentos necessários para o encaminhamento do processo de resolução. 
Portanto, é notória e necessária a utilização de problemas adequados aos objetivos que devem ser atingidos diante de um determinado conteúdo matemático. Contudo, muitos professores acreditam que fazem uso desta metodologia em sala, mas, na verdade, o que frequentemente acontece é a realização de simples exercícios (CLEMENT; TERRAZAN, 2011). Nas palavras de Echeverría e Pozo (1998, p. 16): “[...] Um problema se diferencia de um exercício na medida em que, neste último caso, dispomos e utilizamos mecanismos que nos levam, de forma imediata, à solução". Como exemplo pode-se imaginar uma situação em que o professor acaba de explicar um tópico matemático que requer a utilização de uma fórmula para realização dos cálculos, essa atividade pode ser considerada muito mais um exercício do que um verdadeiro problema (ECHEVERRÍA, 1998).

Além disso, têm-se as situações contextualizadas que, por vezes, também, são erroneamente denominadas problemas. Essas questões por si só, mesmo que possuam um enunciado atraente e relacionado com questões cotidianas, não se constituem necessariamente um problema quando são direcionadas apenas para a aplicação restrita de um algoritmo ou técnica que está sendo estudada.

É importante salientar que um problema tem caráter particular para cada estudante e, conforme Peduzzi (1997) aponta, inicialmente o que constituía um problema para um determinado estudante em um momento, passa a ser um exercício para o mesmo à medida que desenvolve novos conhecimentos e habilidades. Nessa mesma linha de pensamento, Pozo e Angón (1998) afirmam que para um mesmo estudante, uma tarefa, em momentos distintos, pode ser considerada tanto um problema quanto um exercício, e vão além, apontam, também, que uma mesma tarefa pode ser considerada um problema para um estudante e um simples exercício para outro, visto que esta abordagem depende não apenas dos conhecimentos prévios de cada indivíduo, como, também, da forma com que o mesmo se comporta diante da resolução.

Por outro lado, Peduzzi (1997, p. 230) destaca que os exercícios, também, têm um papel importante nas aulas de Matemática:

\footnotetext{
É oportuno, aqui, destacar, e não desmerecer ou relevar a um segundo plano, o papel do exercício nas tarefas escolares. É através dele que o estudante desenvolve e consolida habilidades. Este fato, no entanto, nem sempre fica claro ao aluno, que muitas vezes considera enfadonho, cansativo e sem propósito a repetição continuada de uma certa prática.
}

Devido a isso, concorda-se com a perspectiva de que um problema é uma importante ferramenta para apresentação, exploração, execução de debates e investigações de um conteúdo matemático e que os exercícios podem contribuir quando se deseja consolidar e averiguar aspectos envolvendo cálculos matemáticos. Contudo, é importante não haver a predominância de aulas planejadas em torno da aplicação de exercícios, desprezando o caráter investigativo e estimulante que as aulas de Matemática podem desempenhar a partir da metodologia de resolução de problemas. Por fim, para efeitos de exemplificação, o Quadro 1 apresenta três questões, que ao serem abordadas em uma turma de 60 ano do Ensino Fundamental denotam situações diferentes: 
Quadro 1 - Exemplos de Exercício, Questão Contextualizada e Problema

1. Efetue $(1-3) \cdot(4-9 \div 3)$.

2. De um refrigerante de $2000 \mathrm{ml}$ (2 litros), Ana tomou $250 \mathrm{ml}$ e Maria tomou $500 \mathrm{ml}$. Quanto refrigerante sobrou?

3. Em um país havia um grande hotel que tinha mil quartos e outros tantos empregados. Estes, um dia, dedicaram-se a brincar abrindo e fechando as portas dos mil quartos. No começo, todas as portas estavam fechadas, e o primeiro empregado começou abrindoas todas; depois o segundo empregado, fechando todas as portas pares, e a seguir o terceiro mudando de posição (abrindo se estavam fechadas, fechando se estavam abertas) todas as portas dos quartos que eram múltiplos de 3. O quarto empregado fez o mesmo com todos os quartos múltiplos de 4, e assim foram passando ordenadamente os mil empregados. O último limitou-se a fechar a porta do quarto 1000. Mas como sabemos que estava aberta? Você poderia realmente dizer quais ficaram abertas e quais fechadas? (VILA; CALLEJO, 2006, p. 157)

(Fonte: Exemplos 1 e 2 desenvolvidos pelos autores; Exemplo 3 retirado de Vila e Callejo (2006, p. 157))

Analisando o Quadro 1, tem-se que o primeiro item (1) representa um Exercício, uma vez que o mesmo consiste na simples repetição de técnicas; o segundo item (2) refere-se à uma Questão Contextualizada, pois o enunciado da mesma direciona à aplicação de uma técnica que, provavelmente já foi estudada. Por fim, o terceiro item (3) indica um problema, dado que seu enunciado não remete a utilização específica de alguma técnica, ou seja, é necessário que os estudantes busquem por estratégias, com base nos conhecimentos que já possuem.

É importante salientar, que a questão 3 apresentada à uma turma de Ensino Médio, por exemplo, pode deixar de ser um problema, tornando-se uma questão contextualizada na medida em que os mesmos farão apenas o emprego de técnicas já conhecidas caso ele seja aplicado após os estudantes aprenderem o conteúdo de múltiplos e divisores, não tendo que formular estratégias e não havendo um novo conceito a ser construído. Nessa perspectiva, conforme será melhor discutido na sequência, considera-se um problema como o "ponto de partida para a construção de novos conceitos e novos conteúdos" (ONUCHIC; ALLEVATO, 2011, p. 80).

\section{A METODOLOGIA DE RESOLUÇÃO DE PROBLEMAS}

Como metodologia, a resolução de problemas pode auxiliar no processo de ensino e aprendizagem de conceitos matemáticos, aproximando esses conceitos da realidade dos estudantes, quando utilizada de forma adequada. Araújo (2014) aponta a resolução de problemas como uma metodologia que traz importantes contribuições para o ensino, uma vez que possibilita que o estudante desenvolva seu pensamento matemático de maneira diferenciada, e não apenas com atividades rotineiras. De acordo com Schastai, Silva e Almeida (2012, p. 53):

Partindo do princípio de que os conhecimentos matemáticos dos alunos são ampliados a partir de situações-problema, e de que quando há uma questão para ser resolvida é que se buscam resposta possibilitando o processo 
Nesse contexto, Onuchic (1999, p. 208) aponta a crença de que o uso da metodologia de resolução de problemas pode "ajudar os alunos a compreender os conceitos, os processos e as técnicas operatórias necessárias dentro do trabalho feito em cada unidade temática" como sendo a principal razão pelo seu interesse em abordá-la. A mesma autora destaca que a resolução de problemas deve ser um caminho para a construção de novos conhecimentos, como também para aplicar aquilo que já foi construído anteriormente (ONUCHIC, 1999).

Para Puig e Cérdan (1988, p. 20, apud HUETE; BRAVO, 2006, p. 119) a metodologia de resolução de problemas "tem a ver com a produção de conhecimentos significativos para aquele que aprende. O conhecimento que se valoriza pela sua significação não é o conhecimento transmitido, mas o conhecimento produzido por quem está em situação de aprender". Ou seja, o estudante deixa de reproduzir o conhecimento, e passa a construí-lo por meio da resolução de determinado problema. Assim sendo, Vila e Callejo (2006, p. 94, grifo do autor) destacam que a resolução de um problema é um "ato criativo e, portanto, o processo de resolução não é linear, a inspiração não é automática, o tempo necessário para ele não pode ser previsto e afetividade está fortemente envolvida".

Assim, a metodologia de resolução de problemas, exige do estudante e do professor a criatividade, além disso, permite que o estudante participe da resolução e construção dos conceitos matemáticos, auxiliando desta forma em uma aprendizagem significativa. Quando se fala em aprendizagem significativa segue-se a ideia apresentada por Huete e Bravo (2006, p. 24), que afirmam que:

Uma aprendizagem significativa obriga o aluno a observar, perguntar, formular hipóteses, relacionar conhecimentos novos com os que já possui, tirar conclusões lógicas a partir dos dados obtidos. Enfim exige que construa paralelamente fatos, conceitos, princípios, procedimentos e estratégias relativas ao conhecimento matemático.

Quando confrontados com problemas, os estudantes aprendem a formar estratégias para solucionar o mesmo por meio do planejamento de etapas, e ainda fazendo uso dos erros para buscar novas alternativas. Além disso, os estudantes conquistam o espírito de pesquisa, pois devem consultar, experimentar, organizar dados, sistematizar resultados e ainda fazer a validação das soluções encontradas (BRASIL, 2000). Como faz notar Schastai, Silva e Almeida (2012, p. 56):

[...] considera-se que pela metodologia da Resolução de Problemas desenvolve-se no aluno uma atitude de investigação científica em relação ao que está posto. Quando o aluno questiona as soluções e a situação-problema em si, volta a uma atividade já realizada, sob um novo pensar sobre a situação num processo metacognitivo, ou seja, pensando sobre o que já pensou ou fez.

Onuchic (1999) corrobora com este pensamento quando aponta que os professores quando utilizam desta metodologia, permitem que seus estudantes desenvolvam sua própria compreensão, e conforme essa se torna mais rica, a habilidade em resolver problemas utilizando a Matemática, também, aumenta. Assim sendo, a utilização da metodologia de resolução de problemas auxilia na 
aprendizagem dos estudantes uma vez que, estes se sentem estimulados a buscarem respostas para uma determinada situação, assim como propicia a eles um momento para formulação do pensamento (VILA; CALLEJO, 2006).

O uso de problemas na aprendizagem matemática pode auxiliar os estudantes nos questionamentos pela busca de uma solução, contribuindo para um raciocínio lógico, fazendo com que estes abdiquem do uso de regras padronizadas. Huete e Bravo (2006, p. 71) tratam a resolução de problemas como:

[...] um processo no qual se combinam diferentes elementos que o aluno possui, como os pré-conceitos (em geral, aqueles conhecimentos previamente adquiridos que servem a uma nova situação), as regras, as habilidades... Exige uma grande dose de reflexão e depende de uma excelente provisão de conhecimentos e capacidades, mais que por sua quantidade, por sua clara compreensão. É importante que essa aprendizagem sustente-se na realidade (situações da vida) e que quem aprenda o faça atribuindo, na aplicação matemática, à utilidade que representa.

Para que a aprendizagem por meio da metodologia de resolução de problemas aconteça de forma significativa, o professor é peça fundamental e insubstituível. 0 professor deve ser um mediador ativo, uma vez que ele é o responsável por lançar questões que desafiem os estudantes, e ao mesmo tempo deve ajudá-los a superar as dificuldades encontradas. Além de mediador, ele deve ser o controlador e o incentivador da aprendizagem, levando seus estudantes a pensar antes de realizar qualquer operação (ÁVILA, 2004).

Durante a resolução de problemas o professor deve ir observando o trabalho de seus estudantes, incentivar que os mesmos busquem relacionar com o que já conhecem sobre o conteúdo, bem como fazer uso das técnicas operatórias já estudadas e ainda, estimular que os estudantes troquem ideias entre si. Contudo, durante a resolução de problemas, o professor não deve fornecer as respostas prontas, e sim, demonstrar confiança no que os estudantes vão construindo (ALLEVATO; ONUCHIC, 2014).

Ressalta-se que durante a resolução do problema, ao ser questionado, é importante que o professor indique o caminho por meio de perguntas secundárias, sem fornecer respostas prontas, levando os estudantes a construir suas próprias estratégias e, também, avaliá-las conforme progride na resolução. Chama-se a atenção quanto ao nível de dificuldade do problema que será levado para a sala de aula, este deve ser adequado ao nível escolar dos estudantes, para que a averiguação seja coerente, não se tornando um problema trivial e nem mesmo um problema impossível.

Além do nível de dificuldade do problema, deve-se analisar a familiarização deste com a realidade dos estudantes uma vez que, conforme Clement e Terrazan (2011, p. 88) afirmam, "as atividades de resolução de problemas devem propiciar aos alunos o desenvolvimento de uma aprendizagem que lhes permita não apenas resolver problemas escolares, mas também problemas cotidianos". Ou seja, os problemas levados à sala de aula, não devem distanciar-se da realidade de mundo destes estudantes, como sugestão, aconselha-se que o professor formule problemas com base no cotidiano da comunidade e/ou bairro que esses estudantes convivem. 
Neste contexto, tendo em vista a importância de se utilizar a metodologia de resolução de problemas no processo de ensino e aprendizagem de conceitos matemáticos, percebe-se a necessidade de o professor estar em contínua formação, a fim de buscar sempre aperfeiçoar-se, para assim propiciar situações de aprendizagem através da resolução de problemas que seja familiar dos estudantes (SCHASTAI; SILVA; ALMEIDA, 2012).

\subsection{CAMINHOS PARA SE TRABALHAR COM A RESOLUÇÃO DE PROBLEMAS}

Em suas pesquisas Onuchic e Allevato (2014) identificaram três diferentes formas de se trabalhar com a metodologia de resolução de problemas em sala de aula: (1) o ensino sobre resolução de problemas, (2) o ensino para a resolução de problemas e (3) o ensino através da resolução de problemas.

No ensino sobre resolução de problemas, Onuchic e Allevato (2014), consideram a resolução de problemas como algo novo, como um novo conteúdo que deve ser ensinado. Allevato (2014, p. 213) destaca que o livro escrito por George Polya "tornou-se referência no ensino sobre resolução de problemas. Esta obra pode ser considerada, talvez, o mais importante exemplo entre os trabalhos com teor essencialmente voltado a ensinar sobre resolução de problemas".

Nesta obra, Polya (1995) define os quatro passos da resolução de um problema como: 1) compreender o problema; 2) verificar como os itens estão inter-relacionados para estabelecimento de um plano; 3) execução do plano; 4) retrospecto da resolução. No contexto dos passos de Polya se observa um fazer sistemático e mecânico, com procedimentos para serem seguidos de modo a obter a solução do problema.

O ensino sobre resolução de problemas não é uma abordagem corriqueira em sala de aula da Educação Básica, pois se refere à técnica a ser ensinada. Pode ser exemplificada, porém no contexto da Programação Linear, onde se ensina um procedimento a ser seguido de modo a obter a solução das questões (identificar as variáveis, função objetivo e restrições; aplicar um algoritmo de resolução Simplex; escrever a resposta ao problema). Essa técnica pode ser sistematizada conforme a Figura 1:

Figura 1 - Fluxograma com a estruturação da resolução de um problema.

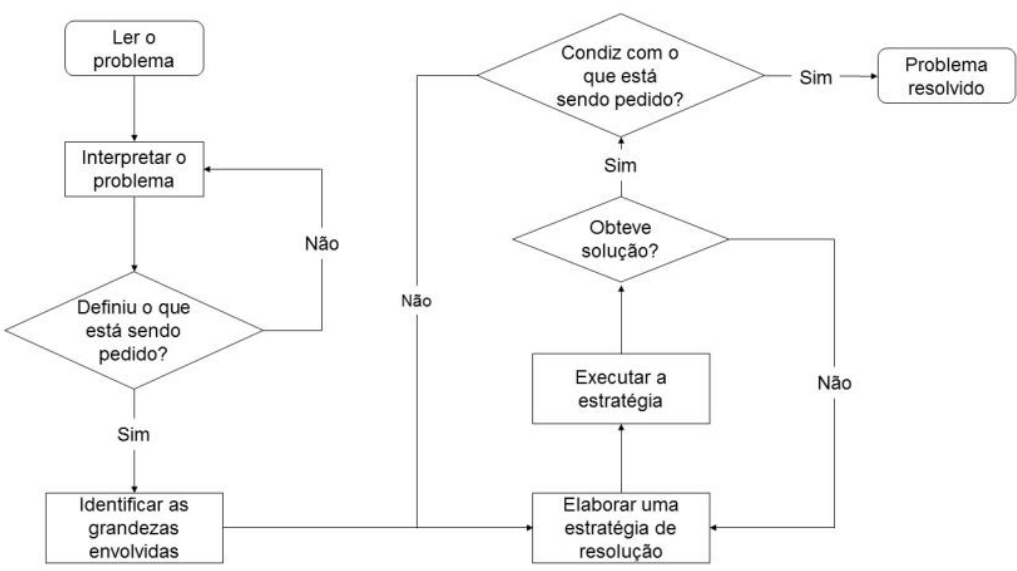

(Fonte: Elaborado pelos autores) 
Nessa concepção de ensino "são abordados temas relacionados à resolução de problemas e percebe-se uma forte ênfase nas heurísticas como forma de orientar os alunos na resolução de problemas, com regras e processos gerais, independentes do conteúdo específico abordado" (ONUCHIC; ALLEVATO, 2014, p. 37). Segundo Allevato $(2014$, p. 213 ) no ensino sobre resolução de problemas "prevalecia a recomendação da adoção e domínio de estratégias, e muitos entenderam que esse domínio seria atingido pela repetição".

No ensino para a resolução de problemas, tem-se como eixo de sustentação a Matemática, considerando a resolução de problemas como um complemento para o ensino, ou seja, explora a forma como e onde o conteúdo matemático ensinado pode ser aplicado na resolução de problemas. Isto é, somente depois de ter estudado a parte teórica do conteúdo é que os problemas são propostos na forma de aplicação. Desta forma, o conteúdo matemático é ensinado separado de suas aplicações, e a resolução de problemas é utilizada para atribuir a significado a este conteúdo através de aplicações (ONUCHIC; ALLEVATO, 2014).

Percebe-se que atualmente a noção que muitos professores têm é a do ensino para a resolução de problemas. Esse ponto de vista leva em consideração a resolução de problemas como uma atividade que poderá ser aplicada apenas após a introdução de algum conceito matemático, ou ainda, após a prática de cálculos (ALLEVATO, 2014). Diante disso, Huete e Bravo (2006, p. 124) se posicionam afirmando que "a resolução de problemas não se situa na conclusão de um tema, nem como um tema separado dos processos de ensino-aprendizagem da matemática; é o núcleo da atividade para a compreensão dos conceitos".

O ensino para a resolução de problemas acontece quando inicialmente apresenta-se o conteúdo matemático e na sequência problemas relacionados com esse conteúdo. Nesse caso, há de se ter o cuidado para não confundir situações contextualizadas (conhecidas como problemas de aplicação ou questões práticas), com problemas.

Dentro desse contexto de se ensinar um conteúdo para depois resolver questões relacionadas a ele, apresentam-se os passos indicados por Clement e Terrazzan (2011, p. 90-91) que foram desenvolvidos a partir de suas pesquisas envolvendo a resolução dessas situações: (1) análise qualitativa do problema; (2) emissão de hipóteses e estimativas; (3) elaboração de estratégia(s) de resolução; (4) aplicação da(s) estratégia(s) de resolução; (5) análise do(s) resultado(s).

No ensino através da resolução de problemas, considera-se a resolução de problemas como um meio de se ensinar conteúdos matemáticos, no qual "o problema é visto como ponto de partida para a construção de novos conceitos e novos conteúdos; os alunos sendo co-construtores de seu próprio conhecimento e, os professores, os responsáveis por conduzir esse processo" (ONUCHIC; ALLEVATO, 2011, p. 80). A partir dessa concepção de se ensinar Matemática através da resolução de problemas,

[...] o GTERP 4 passou a empregar a palavra composta ensino-aprendizagemavaliação, dentro de uma dinâmica de trabalho para a sala de aula, que passamos a entender como uma metodologia. Ao considerar o ensinoaprendizagem-avaliação, isto é, ao ter em mente um trabalho em que estes

\footnotetext{
${ }^{4}$ Grupo de Trabalho e Estudos em Resolução de Problemas da UNESP-Rio Claro/SP.

Página | 221
} 
três elementos ocorrem simultaneamente, pretende-se que, enquanto o professor ensina, o aluno, como um participante ativo, aprenda [sic], e que a avaliação se realize por ambos. $\mathrm{O}$ aluno analisa seus próprios métodos e soluções obtidas para os problemas, visando sempre à construção de conhecimento. Essa forma de trabalho do aluno é consequência de seu pensar matemático, levando-o a elaborar justificativas e a dar sentido ao que faz. De outro lado, o professor avalia o que está ocorrendo e os resultados do processo, com vistas a reorientar as práticas de sala de aula, quando necessário. (ONUCHIC; ALLEVATO, 2011, p. 81, grifo do autor).

Dentro desta metodologia que engloba esses três elementos, ensinoaprendizagem-avaliação, citado pelas autoras, convém salientar que o processo de avaliação da resolução não pode considerar apenas o resultado final, sendo a nota atribuída perante um contexto de certo ou errado, mas sim, deve se pautar a partir do empenho, questionamentos, discussões, raciocínio utilizado, dentre outros aspectos que permeiam o desenvolvimento da resolução. Conforme destaca Cury e Silva $(2008$, p. 87$)$ "Ao avaliar a resolução de um problema não somente pelo produto final mas especialmente pelo processo de solução, podemos analisar a forma como o aluno solucionou a questão, descobrindo suas estratégias, detectando dificuldades e tecendo hipóteses sobre os erros".

Na metodologia de ensino através da resolução de problemas, tem-se como ponto de partida um problema como orientação para a aprendizagem de novos conceitos e conteúdos matemáticos. Nesta, é importante que professor e estudantes trabalhem em conjunto, assim propiciando aos estudantes uma participação efetiva na construção do conhecimento e um espaço para discussões acerca da situação inicialmente proposta (ONUCHIC; ALLEVATO, 2011).

Desta forma, o uso de problemas como ponto de partida pode auxiliar na construção de contextos significativos para os estudantes, uma vez que os estudantes podem fazer uso de conhecimentos que já possuem para solucionar determinado problema, e a partir disso, ir construindo novos conhecimentos. Assim sendo, Huete e Bravo (2006, p. 74) corroboram quando afirmam que "o problema é uma questão que precisa da criatividade de quem aprende, exigindoIhe a incorporação de elementos de aprendizagens precedentes para conseguir sua solução. Quando um problema é resolvido, aprende-se algo novo".

O ensino através da resolução de problemas é aquele em que o conteúdo se desenvolve a partir da necessidade da resolução do problema. Para o professor, a resolução do problema é o meio de se chegar ao ensino de determinado conteúdo matemático, sendo esse o objetivo da proposta, por outro lado, entende-se que para o estudante, o conteúdo matemático é o meio e não a finalidade da proposta, sendo que o aprendizado matemático é consequência do problema resolvido.

Para o ensino através da resolução de problemas, Onuchic e Allevato (2011, p. 83-84) apresentam uma sugestão de trabalho para a sala de aula, organizando as atividades em nove etapas: "(1) preparação do problema, (2) leitura individual, (3) leitura em conjunto, (4) resolução do problema, (5) observar e incentivar, (6) registro das resoluções na lousa, (7) plenária, (8) busca do consenso, (9) formalização do conteúdo.

Observa-se que, nessas etapas, existe também um direcionamento para a discussão em grupo das estratégias a serem utilizadas na resolução do problema. Essa troca de ideias é importante pois, durante as discussões, os estudantes 
expressam suas ideias, justificam suas formas de abordagem e de compreensão da atividade, bem como identificam as técnicas e ferramentas usadas na resolução (ECHEVERRÍA, 1998).

Esse debate propicia um trabalho coletivo em busca da solução do problema, favorecendo uma abordagem através de tentativas diferenciadas de resolução em um mesmo grupo, visto que cada indivíduo aborda o problema de maneira diferente. Essa estratégia é também importante, pois caso aconteçam equívocos durante a resolução, estes podem ser considerados como erros do coletivo, afastando a percepção de fracasso individual que poderia ocorrer caso a resolução fosse restrita a cada estudante.

A presença dos erros durante o percurso da resolução do problema não pode servir como desencorajamento aos estudantes para o prosseguimento da atividade. Com isso, o professor tem papel fundamental em lidar com eles de maneira natural, sem levantar culpados ou desconsiderar toda a trajetória que levou a tais conclusões, mas sim, apontar caminhos que os levem a encontrar novas alternativas ou diferentes abordagens. Echeverría (1998, p. 65) contribui quando afirma: "Nesse sentido, os erros não devem ser tratados como fracassos, mas como fonte de informação para o professor na sua tarefa de "treinador" e para a auto avaliação do aluno".

Desta forma, acredita-se que metodologia de ensino através da resolução de problemas seja uma importante ferramenta que o professor possa utilizar com o intuito de despertar o interesse de seus estudantes para a Matemática e ainda, auxilia também no desenvolvimento crítico e o trabalho coletivo em busca de soluções, tais habilidades são indispensáveis para o convívio pleno em sociedade.

\section{PROPOSTA DE APLICAÇÃO DA METODOLOGIA}

Para fins de exemplificação de como a metodologia através da resolução de problemas pode ser implementada em sala de aula da Educação Básica, apresentase no Quadro 2 uma questão relacionada à Geometria Espacial, que pode ser proposta para estudantes da $2^{a}$ série do Ensino Médio.

\section{Quadro 2 - Questão Contextualizada}

Um artesão faz peças maciças de latão e as vende por $\mathrm{R} \$ 35,00$ o quilo. Fabrício comprou uma dessas peças, que tem a forma de um prisma regular hexagonal de $10 \mathrm{~cm}$ de altura e cuja aresta da base mede $4 \mathrm{~cm}$. Considerando que a densidade do latão é $8,5 \mathrm{~g} / \mathrm{cm}^{3}$, quanto Fabrício pagou pela peça comprada? Use a aproximação $\sqrt{3}=1,7$.

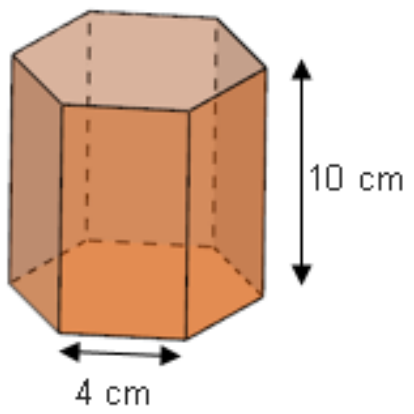

(Fonte: lezzi et al., 2010, p. 196) 
lezzi et al. (2010) apresentam essa questão como um exemplo resolvido, sendo uma Questão Contextualizada com o intuito de reforçar os conteúdos, apresentados anteriormente, relativos à área do hexágono regular e volume de um prisma. Nota-se que, mesmo contextualizada, essa questão não remete à um problema na forma como é proposta, mas sim, pretende a fixação de um conteúdo já discutido.

No Quadro 3, apresenta-se uma reformulação dessa questão, com a intenção de que seja proposta antes da discussão do conteúdo de área do hexágono regular e volume de um prisma e que os mesmos sejam sistematizados após a solução.

Quadro 3 - Reformulação da Questão Contextualizada em um Problema

Questão refeita: Fabrício pretende comprar um recipiente para armazenar 30 litros de cola, que utiliza em suas fabricações de peças de madeira. Para isso, entrou em contato com um artesão para a fabricação de um recipiente produzido de latão que pudesse conter todo produto. $\mathrm{O}$ artesão ofereceu um produto inusitado: um recipiente no formato de um prisma regular de base hexagonal. Fabrício gostou muito de seu formato e solicitou um recipiente semelhante. Contudo, estipulou uma condição: a cola ficará armazenada embaixo de uma prateleira que se encontra a $90 \mathrm{~cm}$ de altura. Ao final do pedido o artesão ficou com a seguinte dúvida: como estipular o preço deste produto? Instigado, foi procurar uma solução na internet, entretanto, a única informação que encontrou foi a densidade do latão que é de $8,5 \mathrm{~g} / \mathrm{cm}^{3}$. Sabendo que esse artesão vende cada quilo de latão por $\mathrm{R} \$ 35,00$, e que a espessura do latão utilizado será de $0,3 \mathrm{~cm}$ como determinar o valor a ser cobrado pelo recipiente?

(Fonte: Adaptado de lezzi et al., 2010, p. 196)

Essa reformulação da questão permitiu modificar uma situação contextualizada para um problema, uma vez que, no contexto dos estudantes da 2a série do Ensino Médio, o conteúdo que será necessário para a resolução da questão não foi previamente ensinado. Seguindo o roteiro, composto de nove etapas, para a utilização da metodologia de resolução de problemas, proposto por Onuchic e Allevato (2011), tem-se a 1a Etapa - Preparação do problema, concluída, uma vez que um problema gerador foi construído, sendo essa uma etapa designada ao professor.

A $2^{a}$ Etapa, consiste na Leitura individual do problema. Após cada estudante ter lido o problema, segue-se para a 3a Etapa - Leitura em conjunto, na qual os estudantes leem e discutem o problema em grupos, podendo o professor auxiliar na compreensão de palavras ou termos desconhecidos.

Nessa etapa de resolução do problema, apresentado no Quadro 3, poderão aparecer dúvidas quanto à compreensão dos conceitos de prisma e de hexágono, bem como entendimento do latão enquanto um material de fabricação, além da ideia de densidade. Para elucidar o conceito de uma figura plana hexagonal, podese questionar os estudantes como é denominada uma figura geométrica com 4 lados e com 5 lados, fazendo-os relembrar a denominação de um hexágono como figura de 6 lados. Para o conceito de prisma e em especial prisma regular, sugerese a pesquisa do termo usando internet ou livros didáticos. Espera-se nessa discussão o entendimento de que, se o prisma é regular, então, o hexágono que 
compõem a base deve ser regular, ou seja, com lados de mesma medida e ângulos congruentes.

As etapas 4 e 5 acontecem simultaneamente, sendo a 4 a etapa - Resolução do problema, orientada para os estudantes, na qual o trabalho colaborativo e em grupo deve prevalecer para a obtenção da solução do problema e construção de novos conceitos matemáticos, enquanto que, a $5 \underline{a}$ etapa - observar e incentivar, refere-se à postura do professor frente a essa metodologia:

O professor incentiva os alunos a utilizarem seus conhecimentos prévios e técnicas operatórias, já conhecidas, necessárias à resolução do problema proposto. Estimula-os a escolher diferentes caminhos (métodos) a partir dos próprios recursos de que dispõem. Entretanto, é necessário que o professor atenda os alunos em suas dificuldades, colocando-se como interventor e questionador. Acompanha suas explorações e ajuda-os, quando necessário, a resolver problemas secundários que podem surgir no decurso da resolução: notação; passagem da linguagem vernácula para a linguagem matemática; conceitos relacionados e técnicas operatórias; a fim de possibilitar a continuação do trabalho. (ONUCHIC; ALLEVATO, 2011, p. 84)

No contexto do problema em questão, o professor deve levar os estudantes à conclusão de que é necessário calcular a área total da superfície do prisma para calcular o custo da fabricação do recipiente. Para tanto, serão necessárias duas medidas: a altura do prisma, que será uma escolha do grupo (não há um valor fixado, apenas o valor máximo) e o valor da aresta que dependerá da altura escolhida. A obtenção do valor da aresta, presume em saber como calcular a capacidade de um prisma, uma vez que conhecendo a capacidade necessária de 30 litros é que será determinado o valor da aresta. Nesse momento, ainda não foi apresentado aos estudantes à formula para cálculo do volume de um prisma, sendo essa uma conclusão do grupo por meio de pesquisa, ou mesmo, pela própria conceituação de volume, que é um dos objetivos de novos conceitos a serem construídos nessa aula. Essas medidas são necessárias para obtenção das áreas da base, que é um hexágono, e das faces laterais, que são retângulos. Os recursos de representação geométrica, podem ser úteis para melhor compreensão, podendo o professor estimular os estudantes à uma representação do sólido em questão e, também, da sua planificação. Para a determinação da área da superfície, tem-se duas figuras geométricas: o retângulo, cujo cálculo da área deve ser relembrado pela equipe; e o hexágono, cujo cálculo da área, também, é alvo de um novo procedimento a ser construído nessa aula. Para instigar os estudantes à compreensão do cálculo da área do hexágono regular ou mesmo para qualquer figura geométrica regular, sugere-se que 0 professor realize alguns questionamentos, se necessário:

(i) É possível decompor essa figura em outra cujo cálculo da área é conhecido?

(ii) Se traçarmos as diagonais do hexágono usando segmentos de reta, que figuras obtemos? Qual a relação entre os lados dessas figuras?

Espera-se que os estudantes, observem que o hexágono pode ser decomposto em 6 triângulos equiláteros, com lados de medida igual da aresta. Ainda, eles devem lembrar de como é calculada a área de um triângulo e utilizar o Teorema 
de Pitágoras para determinar a medida da altura do triângulo. Assim, será possível obter a medida da área da base do prisma e, também, das faces laterais.

Por fim, os estudantes devem calcular o volume do latão, que será usado na confecção do recipiente, para determinação do preço final do produto, relacionando os conceitos de área, volume e densidade.

É importante ressaltar algumas questões frente a etapa de resolução: (i) esse é um problema aberto, devido a não determinação da altura do recipiente, cuja solução final, possivelmente, será diferente para cada grupo, porém os conceitos matemáticos para obtenção da solução serão coincidentes; (ii) o enunciado não define se o recipiente deve ou não ter uma tampa, sendo essa uma determinação do grupo; (iii) os conceitos de capacidade e de volume serão distintos no contexto problema.

Na 6a Etapa - registro das resoluções na lousa, os representantes de cada grupo registram no quadro as soluções obtidas, podendo comentar o caminho para obtenção da solução. Nessa etapa, não é enfatizado se as soluções estão corretas ou não. No caso em questão, é importante discutir com os estudantes e, espera-se que os mesmos cheguem a conclusão, de que as respostas obtidas podem ser diferentes e que se forem iguais, a altura escolhida para o recipiente foi a mesma e as equipes tiveram a mesma decisão em relação ao uso de tampa.

Na 7ạ Etapa - plenária, o professor se coloca como mediador de uma discussão em que cada grupo revela as estratégias usadas para a solução do problema e esclarece as dúvidas que venham a surgir frente a escolhas diferentes que os grupos possam ter feito para a obtenção da solução. Cabe uma discussão, também, no contexto do problema, sobre a utilização ou não de uma tampa, dado a relação custo $\mathrm{x}$ benefício e ao produto que será depositado neste recipiente. A continuidade dessa discussão, leva à 8a Etapa - busca do consenso, onde um caminho de solução correto é definido pelo grande grupo. No problema em questão, não há apenas uma resposta final correta, mas sim um denominador comum sobre os cálculos necessários para obtenção da solução.

Por fim, na 9a Etapa - formalização do conteúdo o professor:

[...] registra na lousa uma apresentação formal - organizada e estruturada em linguagem matemática - padronizando os conceitos, os princípios e os procedimentos construídos através da resolução do problema, destacando as diferentes técnicas operatórias e as demonstrações das propriedades qualificadas sobre o assunto. (ONUCHIC; ALLEVATO, 2011, p. 85, grifo do autor)

No contexto do problema, serão formalizados os novos conceitos construídos, a citar: definição de prisma regular, volume de um prisma, área de um hexágono regular e volume de um prisma de base hexagonal. Também, sugere-se organizar de forma sistematizada os conceitos que foram relembrados: área de um triângulo, área de uma triângulo equilátero e Teorema de Pitágoras.

Essa proposta de atividade tem como finalidade mostrar, como uma questão presente em livro didático com a finalidade de ensino para a resolução de problemas, pode ser adaptada para o ensino através da resolução de problemas. Dessa forma, a resolução de problemas é utilizada como uma metodologia de ensino, na essência de sua formulação, ou seja, um novo conhecimento 
matemático é construído pelos próprios estudantes, protagonistas da própria aprendizagem, e sistematizado pelo professor, que age como mediador no processo de ensino e aprendizagem.

\section{CONSIDERAÇÕES FINAIS}

As reflexões acerca do uso da metodologia de resolução de problemas no decorrer deste estudo, buscaram elucidar quais os componentes necessários para que a utilização desta viesse a contribuir de fato, no processo de ensino e aprendizagem no contexto escolar. Ainda, procurou-se mostrar a diferença entre as diversas ferramentas matemáticas que muitas das vezes são utilizadas em sala de aula como sinônimos de problemas, mas que na verdade, não constituem a utilização desta metodologia de forma correta.

Ademais, apresentou-se uma proposta de atividade direcionada para estudantes da 2a série do Ensino Médio abordando a Geometria Espacial, visando a construção conjunta (professor e estudantes) da definição de prisma regular, volume de um prisma, área de um hexágono regular e volume de um prisma de base hexagonal.

Diante do apresentado, acredita-se que a utilização da metodologia de ensino através da resolução de problemas no processo de ensino e aprendizagem da Matemática em sala de aula é significante, uma vez que possibilita aos estudantes participarem da construção dos conceitos matemáticos. Além disso, viabiliza a aproximação desses conceitos com o mundo real dos estudantes, proporcionando desta forma, uma aprendizagem significativa.

Através desta proposta e das reflexões sobre o uso da metodologia de resolução de problemas, espera-se despertar nos professores o interesse em fazer uso desta metodologia em sala de aula e elucidar sobre a forma adequada de sua utilização. Com relação aos estudantes, espera-se oportunizar a participação dos mesmos na construção dos conceitos, e, ainda, auxiliar no desenvolvimento de uma aprendizagem significativa. 


\title{
Problem solving methodology: conceptions and teaching strategies
}

\begin{abstract}
This bibliographical research aims to present some reflections about the use of the methodology of problem solving in the school context. Initially, some historic conceptions about problem solving are related to the Modern Mathematics Movement. Later, we distinguish exercise, contextualized question and problem, since they are sometimes misused as synonyms. Next, we analyze the contributions and limitations of the use of teaching on, to and through the resolution of problems in the teaching and learning process of mathematical concepts and, finally, a proposal of teaching through problem solving is presented. This activity proposal is intended for students of the second grade of High School and aims to assist in the construction of concepts of Space Geometry. It is hoped by this reflection, to awaken in teachers the interest in using problem solving in the classroom, in order to promote meaningful learning.
\end{abstract}

KEYWORDS: Mathematics teaching. Problem solving. Classroom. 


\section{REFERÊNCIAS}

ALLEVATO, N. S. G. Trabalhar através da Resolução de Problemas: Possibilidades em dois diferentes contextos. VIDYA EDUCAÇÃO, Santa Maria, v. 34, n. 1, p. 209232, jun. 2014.

ALLEVATO, N. S. G.; ONUCHIC, L. de L. R. Ensino-Aprendizagem-Avaliação de Matemática: por que Através da Resolução de Problemas? In: ONUCHIC, L. de L. R. (Org.). Resolução de Problemas: Teoria e Prática. Jundiaí: Paco Editorial, 2014. p. 35-52.

ARAÚJO, A. I. S. de. Trabalhando a Resolução e Exploração de Problemas como uma Metodologia de Ensino de Matemática. In: Encontro Brasileiro de Estudantes de Pós-Graduação em Educação Matemática, 18., 2014, Recife. Anais... Recife: Grupo Lematec - Edumatec/UFPE, 2014. p. 1-9.

ÁVILA, M. G. de. História da Matemática e Resolução de Problemas: Uma Aliança Possível. 2004. 185 f. Dissertação (Mestrado) - Curso de Programa de Pós-Graduação em Ensino de Ciências e Matemática, Universidade Luterana do Brasil, Canoas, 2004.

BERTI, N. O Ensino de Matemática no Brasil: Aspectos para uma Compreensão Histórica. In: Jornada do Histedbr História, Sociedade e Educação no Brasil, 6., 2005, Ponta Grossa. Caderno de Resumos. Campinas: Graf. Fe: Histedbr, 2005. p. 1-18. Disponível em:

<http://www.histedbr.fe.unicamp.br/acer_histedbr/jornada/jornada6/resumos/ 617.htm>. Acesso em: 01 mar. 2017.

BRASIL. M. E. C. Parâmetros Curriculares Nacionais para o ensino médio: Matemática. Brasília: Ministério da Educação e Cultura, 2000.

CLEMENT, L.; TERRAZZAN, E. A. Atividades Didáticas de Resolução de Problemas e o Ensino de Conteúdos Procedimentais. Revista Electrónica de Investigación en Educación en Ciencias, Buenos Aires, v. 6, n. 1, p. 87-101, jul. 2011.

DINIZ, M. I. O Olhar do Formador de Professores para a Pesquisa em Resolução de Problemas no Brasil. In: SEMINÁRIO EM RESOLUÇÃO DE PROBLEMAS, 2, 2011, Rio Claro. Anais... Rio Claro: Unesp, 2011. p. 1-12.

CURY, H. N.; SILVA, P. N. da. Análise de erros em resolução de problemas: uma experiência de estágio em um curso de licenciatura em matemática. Revista Brasileira de Ensino de Ciência e Tecnologia, Ponta Grossa, v. 1, n. 1, p. 85-97, abr. 2008. 
DOBROWOLSKI, E. N.; PINTO, N. B. Movimento da Matemática Moderna nas práticas escolares e suas repercussões na maneira de ensinar. In: Congresso Nacional de Educação, 9., 2009, Paraná. Anais... Paraná: PUC, 2009. p. 4164 4171.

ECHEVERRÍA, M. del P. P. A Solução de Problemas em Matemática. In: POZO, J. I. A Solução de Problemas: Aprender a resolver, resolver para aprender. Porto Alegre: Artmed, 1998. p. 43-65.

ECHEVERRÍA, M. del P. P.; POZO, J. I. Aprender a resolver problemas e resolver problemas para aprender. In: POZO, J. I. A solução de problemas: Aprender a resolver, resolver para aprender. Porto Alegre: Artmed, 1998. p. 13-42.

FIORENTINI, D. Alguns modos de ver e conceber o ensino da Matemática no Brasil. Zetetiké. Campinas, SP: UNICAMP, Ano 3, n. 4, 1995.

HUETE, J. C. S.; BRAVO, J. A. F. O ensino da matemática: fundamentos teóricos e bases psicopedagógicas. Porto Alegre: Artmed, 2006. Tradução Ernani Rosa.

IEZZI, G. et al. Matemática: Ciência e Aplicações. 6. ed. São Paulo: Editora Saraiva, 2010.

NCTM. An Agenda for Action: Recommendations for School Mathematics of the 1980s. 1980. Disponível em:

<http://www.nctm.org/flipbooks/standards/agendaforaction/index.html>. Acesso em: 05 mar. 2017.

ONUCHIC, L. de L. R. Ensino-Aprendizagem de Matemática através da Resolução de Problemas. In: BICUDO, M. A. V. (Org.). Pesquisa em Educação Matemática: Concepções \& Perspectivas. São Paulo: Unesp, 1999. p. 199-218.

ONUCHIC, L. de L. R.; ALLEVATO, N. S. G. Pesquisa em Resolução de Problemas: caminhos, avanços e novas perspectivas. Boletim de Educação Matemática, Rio Claro, v. 25, n. 41, p. 73-98, dez. 2011.

ONUCHIC, L. de L. R.; ALLEVATO, N. S. G. Novas reflexões sobre o ensinoaprendizagem de Matemática através da Resolução de Problemas. In: BICUDO, M. A. V.; BORBA, M. C. (Org.). Educação Matemática: pesquisa em movimento. São Paulo: Cortez Editora, 2004. p. 213-231. 
PEDUZZI, L. O. de Q. Sobre a resolução de problemas no ensino da

Física. Caderno Brasileiro de Ensino de Física, Florianópolis, v. 14, n. 3, p. 229 253, dez. 1997.

POLYA, G. A arte de resolver problemas. 2. ed. Rio de Janeiro: Interciência, 1995. Tradução e adaptação Heitor Lisboa de Araújo.

POZO, J. I.; ANGÓN, Y. P. A Solução de Problemas como Conteúdo Procedimental da Educação Básica. In: POZO, J. I. A Solução de Problemas: Aprender a resolver, resolver para aprender. Porto Alegre: Artmed, 1998. p. 139-165.

SCHASTAI, M. B.; SILVA, S. de C. R. da; ALMEIDA, M. de F. M. de. Resolução de problemas - Uma perspectiva no ensino de matemática. Revista Brasileira de Ensino de Ciência e Tecnologia, Ponta Grossa, v. 5, n. 3, p. 52-69, jan. 2012.

VILA, A.; CALLEJO, M. L. Matemática para aprender a pensar: O papel das crenças na resolução de problemas. Porto Alegre: Artmed, 2006. 212 p.
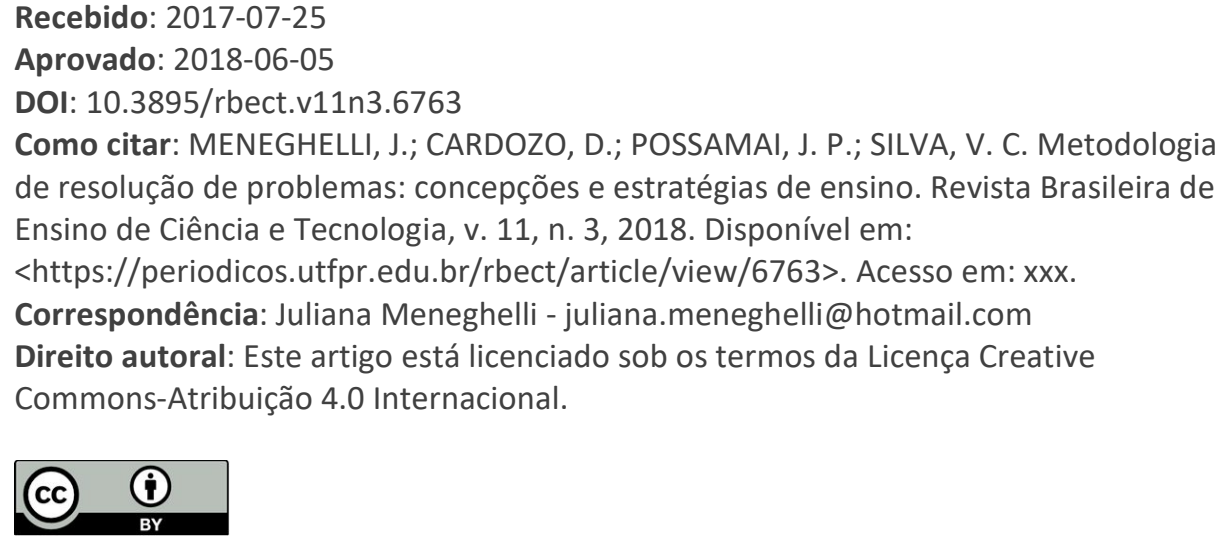